\title{
The impact of information on wine auction prices: results of an experiment*
}

\author{
Sébastien Lecocq† Thierry Magnac $\ddagger$ \\ Marie-Claude Pichery§ and Michael Visser $₫$
}

February 2004

${ }^{*}$ We wish to thank our colleagues at INRA-LEA for their comments on the experimental design during a pilot study. We also thank 2 referees, J. Abbring, O. Ashenfelter, H. Houba, I. McAvinchey, L. Muus, D. Reiley, and Q. Vuong for many helpful suggestions and remarks. Financial support from INRA (AIP Consommation et Comportement Alimentaire) is gratefully acknowledged.

${ }^{\dagger}$ INRA-CORELA, 65 boulevard de Brandebourg, 94205 Ivry-sur-Seine, France. E-mail: lecocq@ivry.inra.fr

¥INRA-Paris Jourdan, 48 boulevard Jourdan, 75014 Paris, France, and CREST, 15 boulevard Gabriel Péri, 92240 Malakoff, France. E-mail: tmagnac@ens.fr.

${ }^{\S}$ LATEC, Pôle d'Economie et Gestion, 2 boulevard Gabriel, 21000 Dijon, France. E-mail: pichmc@u-bourgogne.fr.

IINRA-CORELA, 65 boulevard de Brandebourg, 94205 Ivry-sur-Seine, France. E-mail: visser@ivry.inra.fr. 


\title{
Résumé
}

Ce travail présente les résultats d'une enchère expérimentale de vin. Les participants de l'expérience ont été répartis de façon aléatoire dans trois salles. Dans chaque salle, quatre vins étaient évalués, mais le niveau d'information auquel les participants avaient accès différait d'une salle à l'autre. Une fois les évaluations terminées, les vins étaient vendus séquentiellement lors de quatre enchères Vickrey indépendantes avec prix de réserve secrets. Nous trouvons que certaines caractéristiques socio-économiques comme le sexe, le revenu et les habitudes de consommation, ont un effet significatif sur la disposition à payer pour un vin, alors que d'autres comme l'âge et la nationalité n'en ont pas. Nous trouvons également qu'une fois que les individus ont lu les caractéristiques des étiquettes et qu'ils ont consulté les extraits de guides, le goût des vins n'a pas d'effet supplémentaire sur la disposition à payer. En revanche, si les individus qui ont dégusté les vins à l'aveugle sont informés des caractéristiques des étiquettes et des appréciations des spécialistes, leur disposition à payer augmente substantiellement.

\begin{abstract}
This paper reports the results of an experimental wine auction. Participants of the experiment were randomly assigned to three rooms. In each room four wines had to be evaluated, but the level of information to which participants had access differed across rooms. After the evaluations, the wines were sold sequentially, by four separate Vickrey auctions with secret reservation prices. We find that certain socio-economic characteristics such as gender, income and consumption habits, have a significant impact on the willingness to pay for wine, while others such as age and nationality, do not. We also find that once individuals have read the label characteristics and extracts from wine guides, the taste of the wines does not have an additional impact on willingness to pay. Conversely, if individuals who have only tasted the wines blindly are informed about the wine characteristics and opinions from experts, their willingness to pay increases substantially.
\end{abstract}

Keywords: Auction; Field experiment; Information; Willingness to pay; Wine price.

J.E.L. classification numbers: C93; D8; D44. 


\section{Introduction}

The willingness to pay for a consumption good depends, among other things, on the degree of product-information that is available to the consumer. A consumer that knows all the relevant product-characteristics will put a different value on the good than a consumer that is for some reason only partially informed. There are many situations in which it is important to learn how willingness to pay is affected by the extent to which consumers are informed about a product. For example, in launching a new food product, it is crucial for the producer to know how potential buyers are influenced by package descriptions and the taste of the product; for manufacturers of durable goods like cars or televisions, it is important to know how potential buyers react to consumer reports and different forms of publicity; before starting a campaign to inform the public on an epidemic like BSE, it is important for the authorities to anticipate its effects on beef consumption.

In this paper we establish empirically how the willingness to pay for wine depends on the degree of wine-information that is available to the consumer. Although a study of the link between willingness to pay and information could be interesting for other types of consumption goods also, the issue appears particularly relevant in the case of wine. Note that field data, such as data from wine sales at auction houses, would not enable us to estimate the impact of information on the willingness to pay for wine. The data that auction houses like Christie's and Sotheby's make public in their sales catalogues and auctioneer's books (see Ashenfelter (1989), Ginsburgh (1998), and McAfee and Vincent (1993) for empirical analyses of these data sources) contain detailed descriptions of the wines that were auctioned and the (winning) bids that were submitted, but they reveal nothing about the level of information to which the bidders had access. For the same reason, contingent valuation survey data would not be very helpful either.

To obtain the necessary data, we therefore organized an experimental wine auction. The auction took place during a scientific conference on oenometrics, and the people (mainly economists, but also some medical doctors and specialists in marketing) that attended this conference were the actual participants of the experiment. The participants were randomly assigned to three conference rooms. In each room the experiment was made up of two parts: in the first part the participants were required to evaluate four wines, and in the second part these wines were sold by auction. The first part of the experiment was different in the three rooms. Although the same four wines were evaluated in each room, the type of information to which participants had access differed from room to room. The participants in room 1 could see the labels on the wine bottles, they could read extracts from influential wine guides and all sorts of technical details about each wine, and they could taste the wines. Compared to room 1, the participants in the other two rooms were partially informed. The participants in room 2 could read the labels, the guide extracts and the technical details, but they were not given the possibility to taste the wines. Inversely, the participants in room 3 could taste the wines but could not read the labels, guide 
extracts and technical details. The second part of the experiment was identical in the three rooms. Once the wines were evaluated in a room, they were sold sequentially, i.e. one after the other, by four separate sealed-bid second-price auctions (also known as Vickrey auctions) with secret reservation prices. After each auction round the winner of the wine was announced, if there was one, but the participants were not informed about any of the submitted bids nor about the reservation price of the wine.

The data of this experiment are analyzed under the assumption that the participants in a room had independent private values ${ }^{1}$ for a wine (but each participant's values could differ across the wines that were auctioned). As is well known, in a standard single-object private-value Vickrey auction, the dominant strategy for agents is to bid their private value for the object, i.e. it is optimal for agents to bid their willingness to pay (this is precisely the reason why this auction mechanism was chosen by us). As described above, we did not sell one but several objects. We show that some additional assumptions are needed to ensure that the participants submitted bids equal to their valuation for the wines in this more general context as well. Given these assumptions and the fact that the assignment of participants to rooms was randomized, it follows that for each wine the effect of taste (resp. label characteristics and wine guides) on the willingness to pay is identified by simply contrasting the distribution of bids in room 1 with the distribution of bids in room 2 (resp. room 3 ).

The paper proceeds as follows. In the next section we describe the design of the experiment. Section 3 shows under which conditions it is optimal for bidders to bid their willingness to pay in sequential Vickrey auctions. Section 4 presents the empirical results, and section 5 concludes.

\section{The experiment}

The experiment was conducted during the VI-th Oenometrics conference. This two-day conference took place in October 1998 in Ajaccio, the largest city on the French island of Corsica. Our experimental session was scheduled on the first day of the conference, just after the keynote speech. After the keynote speaker had finished his talk, one of us reminded the conference participants that an experimental wine auction was about to take place. It was explained that those willing to participate in the experiment had to draw a number from a box, and that the number would randomly assign them to one out of three smaller conference rooms. Each individual who actually drew a number was directed to the selected conference room, and was seated at a table with his/her number written on it. On each table there was a letter and an envelope containing all material for the experiment. All individuals were required to read the letter but not open the envelope. The letter informed them about the conditions under which the experiment would be held. As the experimental conditions were slightly different in the three rooms, the letters differed somewhat from

\footnotetext{
${ }^{1}$ Note that McAfee and Vincent (1993) also adopt the independent private value paradigm in their theoretical explanation of the declining price anomaly observed in wine auction data.
} 
room to room. They can be found in the appendix. ${ }^{2}$ We asked individuals who accepted the conditions and who wanted to participate in the experiment to sign the letter. ${ }^{3}$ After all the letters were collected in a given room, the door was closed and the experiment started.

The three experiments began more or less simultaneously. In each room one of us was the experimenter. We were assisted by students from the Ecole du Commerce et de la Distribution d'Ajaccio (two students in room 1, and one in rooms 2 and 3). In each room we began the session by reading, aloud and in English, an introduction: we welcomed the subjects, asked them not to communicate or interact with each other, and told them to raise their hand if at some point during the session they had a question; we then said that we would start reading the instructions in English, and that they could find written versions of the text, one in English and one in French, among the material contained in their envelope. These instructions can be found in the appendix.

In each room we first asked the subjects to answer a number of questions concerning their socio-economic characteristics (they were asked to fill in parts $\mathrm{A}$ and $\mathrm{B}$ of the questionnaire; the questionnaire was identical in each room and is given in the appendix). The session then proceeded with an evaluation of four different wines. Although the same four wines were evaluated in the three rooms, the type of evaluation differed from room to room. In room 1 the wines were evaluated as follows. First the subjects were required to look carefully at four wine description forms that were included in their envelopes. Each form was numbered $1,2,3$, or 4 and contained a photo of the label of the wine bottle as well as some additional information concerning the product such as technical details on production techniques and vinification methods, extracts from wine guides, and publicity by the wine producer. ${ }^{4}$ Once the subjects had read the wine descriptions, they were served four transparent and plastic cups, each one filled with approximately $3 \mathrm{cl}$ of wine. Each cup was numbered, again between 1 and 4 . Subjects were told that there was a one-to-one correspondence between cups and wine descriptions, i.e. the wine in say cup $\mathrm{j}$ corresponded to the wine described in form $\mathrm{j}$. We gave the subjects some bread and asked them to taste the wines. After all subjects had finished tasting the wines (the majority of subjects completely drank all their cups), we asked them to grade each product in view of its description form and its taste. Each wine had to be graded on a scale from 0 (very bad) to 10 (very good), and all grades had to be reported in part $\mathrm{C}$ of the questionnaire form. We told subjects that the questionnaires would be collected, and advised them to copy their grades on a separate piece of paper. We recommended the subjects to do this because we expected that the grades could help them in determining the wine bids in the second part of

\footnotetext{
${ }^{2}$ Since the conference took place in France, and since many conference participants were French, these letters and all the other documents used in the experiment were written in English and in French. We only publish the English versions.

${ }^{3}$ It turned out that all persons who had drawn a number signed the letter. Hereafter these persons will be referred to as the subjects.

${ }^{4}$ The four wine description forms are available upon request or can be found as an appendix to the working paper 04-01 at http://www.inra.fr/ESR/UR/lea/document.htm.
} 
the experiment.

The subjects in room 2 had the opportunity to read the four descriptions forms, but were not allowed to actually taste the wines. ${ }^{5}$ Here the subjects had to evaluate the wines on the basis of wine descriptions only. The subjects in room 3 had the opportunity to taste the wines, but did not get access to the wine description forms. Here the wines were thus evaluated blindly. The subjects got some bread, and here as well most of them drank all the wine. Similarly as in room 1, the subjects in rooms 2 and 3 were asked to grade each wine on a 0-10 scale, and report all grades in part $\mathrm{C}$ of the questionnaire. Subjects were again encouraged to copy the grades before we collected the questionnaire forms.

Once the four wines were evaluated in a given room we proceeded with the wine auction. This second part of the experiment was completely identical in each of the three rooms. We told subjects that the wines they had just evaluated would be auctioned separately, first wine 1, then wine 2, etc..., and that each wine would be sold per lot of six bottles at a Vickrey auction with a secret reservation price fixed by us. We explained this auction mechanism and illustrated it with two examples. We made sure that all subjects understood the principle. The subjects were told that the winner had to pay the winning price to us and that the wine bottles would be sent to her/his home address without any additional charges. We told them that the secret reservation prices were equal to the wholesale prices of the wines, and showed them four small envelopes containing our reservation prices. The reservation prices remained secret during the experiment, but we told subjects that they could, if they wished, consult the envelopes at the end of the session.

Subjects could bid for a particular wine, by picking the appropriate small envelope (there were four of them in the big envelope, each one numbered between 1 and 4), by indicating on the included piece of paper their bid, and by reinserting the piece of paper in the small envelope. We explained them that once all bids (for the wine that was to be auctioned) were submitted, we would collect the corresponding envelopes and compare the bids. We told them that if there was no winner, we would directly move on the next auction round, without making public any of the submitted bids. If there was one, we would announce the winner's identification number, ask the winner to come to us and reveal her/his name, and then continue with the next round, again without revealing the submitted bids. In case the highest bid was submitted by two or more subjects simultaneously, we would select the winner at random among these subjects. It is important to stress that the bids were submitted and collected separately. That is, in each auction round, the participants were requested to bid only for the particular wine that was on sale in the auction round; similarly, we only collected the envelopes corresponding to the wine that was sold during the current auction round.

We finally gave the subjects five minutes to read the instructions on their own, checked if there were questions, and when there were no longer any we proceeded with the sale by auction of the wines.

\footnotetext{
${ }^{5}$ For fairness reasons they could, however, taste the wines at the end of the experiment.
} 
Thirty two individuals participated in the experiment: 10 of them were randomly assigned to room 1,11 to room 2 , and 11 to room $3 .^{6}$ Since 56 individuals were registered at the conference, this implies a participation rate of $57 \%$. After the experiment we talked with the non-participants, and it turned out that they had various reasons for their refusal. Some non-participants had objections of principle to auctions; others perceived auctions as something too risky and were afraid of losing money; still others indicated that they had no extra luggage space or mentioned that they lacked liquidity. Clearly, the last group of individuals might have participated if we had told them before the start of the experiment a) that the bottles were sent to their home address and b) that it was not necessary to pay in cash.

Before turning to the next section, we comment on the products chosen for this study. Unlike most experimental auction studies, ${ }^{7}$ we have chosen real products, and not artificial or fictitious ones. The disadvantage of this choice was that it implied a loss of experimental control over certain economic variables. For instance, we had no control over individual preferences like in laboratory auctions (see for a survey Kagel, 1995). In laboratory auctions, the value of an artificial good is typically represented by a random drawing from some distribution function, implying that individual preferences can be observed and controlled by the experimenter. The obvious advantage of real goods over artificial ones was that they rendered the experiment more realistic and more similar to field auctions.

The four wines selected for this study were all red wines. Wine 1 (Beaune Bressandes) and wine 2 (Nuits Saint Georges) were Burgundy wines, wine 3 (Château Berliquet) and wine 4 (Château Haut-Marbuzet) are Bordeaux wines. In October 1998, when the experiment was conducted, these wines were still very young - wines 1, 2, and 3 were from the 1995 vintage, and wine 4 from the 1996 vintage - and not yet mature. At that time it was thought that the wines had a good ageing potential and that they had to be kept for a period varying between 3 to 15 years before reaching their optimum. The four wines were bought by us directly at the château or at the domain. The prices per lot of six bottles were FFr660, FFr570, FFr660, and FFr900 respectively. We fixed the reservation prices per lot of six bottles at FFr600, FFr510, FFr600, and FFr840 respectively. Since the purchase prices did not include the profit margin usually added by retailers, and since we substracted FFr60 per lot of six bottles for each wine, our reservation prices were reminiscent of wholesale prices. It should be mentioned that whereas the Bordeaux wines could easily be found on the market, the Burgundy wines could not because they were produced in small quantities. After the wines were bought and sent to Ajaccio (for the wine

\footnotetext{
${ }^{6}$ Initially the box contained only thirty numbers: the first ten numbers for room1, the first ten for room2, and the first ten for room3. When there were no more numbers left, i.e. when thirty individuals had picked a number, the person who stood with the box discreetly put in the next thirty numbers (the next ten numbers for room1, etc.). The purpose of this sampling mechanism was to avoid a too unequal distribution of subjects among the three rooms.

${ }^{7}$ Lucking-Reiley (1999) is one of the exceptions we are aware of. He studied the revenue equivalence theorem using data from auctions for collectible trading cards. His data were generated in experiments conducted over the Internet.
} 
tastings we sent 6 bottles of each wine to Ajaccio), we realized that our two Bordeaux wines were also included in the sample of wines used by Combris, Lecocq and Visser (1997) to estimate a hedonic price equation for Bordeaux wines. All the 541 wines in that sample were blindly evaluated and then graded on a 0-20 scale by expert tasters. Château Haut-Marbuzet received a 16.75 from the experts, the second highest grade in the sample, and château Berliquet a 12.25, which was slightly higher than the average grade in the sample (11.21).

\section{Sequential Vickrey auctions}

The models that are considered in the theoretical literature on multiple-object sequential auctions do not fully capture all the specific features of our experimental auction, so that the results and implications of this literature are not directly applicable to our setting. Most models assume for instance that each participant only wants one object, i.e. there is no utility associated with obtaining a second object (Bernhardt and Scoones, 1994; Engelbrecht-Wiggans, 1994; Gale and Hausch, 1994; McAfee and Vincent, 1993; Weber, 1983). Since the subjects in our experiment could in principle buy more than one type of wine, this assumption is clearly too restrictive in our case. Some models do allow the agents to have multiple-object demand functions (Black and de Meza, 1992; von der Fehr and Riis, 1999), but still do not reflect all aspects of our experimental auction. Black and de Meza assume for instance that the objects to be auctioned are strictly identical. Furthermore, their auction mechanism differs from ours in that the winner of the first object has the option to buy the other objects at the first-round winning price. Von der Fehr and Riis consider sequential Vickrey auctions in which the objects are allowed to differ, but they suppose that at the start of the first round agents do not know their valuations for the objects sold in subsequent rounds (this assumption can clearly not hold in our case since the subjects evaluated all wines before the start of the auctions). Furthermore, they assume that there are no reservation prices, thereby implicitly assuming that there is a winner in each auction round.

In this section we show what the optimal bidding strategies are in privatevalue sequential Vickrey auctions, and under which conditions it is optimal for bidders to bid their willingness to pay. For this purpose we consider a model that draws on the model proposed by von der Fehr and Riis, but which differs in two respects: we assume that at the start of the game agents know their private values for all objects, and we incorporate secret reservation prices in the model.

Assume that there are just two risk-neutral players, indexed by $i=A, B$, and two objects (denoted 1 and 2). The objects are allowed to be different and are sold sequentially. At the start of the game, each player knows her/his private valuations for the two objects, but not those of the other player. Let $v_{i}^{1}$ denote $i$ 's valuation of the first object. Let $v_{i}^{2 W}$ denote the valuation of the second object if agent $i$ wins the first object and $v_{i}^{2}$ if he/she does not. We assume that the parameter $\delta \equiv v_{i}^{2 W}-v_{i}^{2}$ is the same for both agents and is common knowledge. If the objects are substitutes then $\delta<0$; if they are 
complements then $\delta>0$. The valuations $v_{A}^{1}$ and $v_{A}^{2}$ (resp. $v_{B}^{1}$ and $v_{B}^{2}$ ) are allowed to be dependent variables. The pair of values $\left(v_{A}^{1}, v_{A}^{2}\right)$ is independent from the pair $\left(v_{B}^{1}, v_{B}^{2}\right)$, and both pairs are drawn from the same, commonly known, distribution function. The reservation prices for the two objects are denoted $p^{1}$ and $p^{2}$. The prices are allowed to be dependent variables, but they are assumed to be independent of the values $v_{i}^{1}$ and $v_{i}^{2}, i=A, B$, and their distribution function (as perceived by the players) is also common knowledge.

To determine the optimal strategy in this two-stage game, we proceed by backward induction. In the second auction, the optimal bidding strategy of each player is to submit a bid equal to its valuation (Vickrey, 1961), i.e. player $i$ submits either $v_{i}^{2}$ or $v_{i}^{2}+\delta$, depending on whether the player lost or won the first auction round. Let us denote $\beta($.) the symmetric increasing equilibrium bidding function in the first auction. The equilibrium bidding function maps, for each player $i$, the value $v_{i}^{1}$ into a bid $\beta\left(v_{i}^{1}\right)$. Assume now that in the first auction player $B$ behaves according to this equilibrium strategy, so that player $B$ submits $\beta\left(v_{B}^{1}\right)$. Then, if in the first auction player $A$ submits $b_{A}$, her/his expected profit function is given by

$$
\begin{gathered}
\pi\left(b_{A} ; v_{A}^{1}, v_{A}^{2}\right)= \\
\int_{b_{A}>\beta\left(v_{B}^{1}\right)>p^{1}}\left\{v_{A}^{1}-\beta\left(v_{B}^{1}\right)\right\}+E\left[\max \left(v_{A}^{2}+\delta-v_{B}^{2}, 0\right) \mathbf{1}\left\{v_{B}^{2}>p^{2}\right\} \mid v_{B}^{1}, p^{1}\right] d G_{v_{B}^{1}}\left(v_{B}^{1}\right) d F_{p^{1}}\left(p^{1}\right) \\
+\int_{p^{1}<b_{A}<\beta\left(v_{B}^{1}\right)} E\left[\max \left(v_{A}^{2}-v_{B}^{2}-\delta, 0\right) \mathbf{1}\left\{v_{B}^{2}+\delta>p^{2}\right\} \mid v_{B}^{1}, p^{1}\right] d G_{v_{B}^{1}}\left(v_{B}^{1}\right) d F_{p^{1}}\left(p^{1}\right) \\
+\int_{p^{1}>b_{A} \text { or } p^{1}>\beta\left(v_{B}^{1}\right)} E\left[\max \left(v_{A}^{2}-v_{B}^{2}, 0\right) \mathbf{1}\left\{v_{B}^{2}>p^{2}\right\} \mid v_{B}^{1}, p^{1}\right] d G_{v_{B}^{1}}\left(v_{B}^{1}\right) d F_{p^{1}}\left(p^{1}\right)
\end{gathered}
$$

where $\mathbf{1}\{$.$\} is the indicator function, equal to one if its argument is true and$ zero otherwise, $E[. \mid$.$] denotes a conditional expectation, and F_{p^{1}}($.$) and G_{v_{B}^{1}}($. represent the marginal distribution functions of $p^{1}$ and $v_{B}^{1}$. The first term corresponds to the case where player $A$ wins the first auction, the second term to the case where player $B$ wins the first auction, and the third term to the case where neither player wins the first auction. Recall here that the object was only sold if the second highest bid was above or equal to the reservation price. Also recall that no information whatsoever was released between auction rounds. However, this is not a crucial point since it can be shown that player's A strategy in the second round and expected profit function remain unchanged in a situation where private values and the reservation price of the first object are made public after the first round.

Deriving the expected profit function with respect to $b_{A}$ gives

$$
\begin{gathered}
\frac{\partial}{\partial b_{A}} \pi\left(b_{A} ; v_{A}^{1}, v_{A}^{2}\right)= \\
\frac{\partial \beta^{-1}\left(b_{A}\right)}{\partial b_{A}} g_{v_{B}^{1}}\left(\beta^{-1}\left(b_{A}\right)\right) F_{p^{1}}\left(b_{A}\right)\left(v_{A}^{1}-b_{A}\right)
\end{gathered}
$$




$$
\begin{gathered}
+\frac{\partial \beta^{-1}\left(b_{A}\right)}{\partial b_{A}} g_{v_{B}^{1}}\left(\beta^{-1}\left(b_{A}\right)\right) E\left[\max \left(v_{A}^{2}+\delta-v_{B}^{2}, 0\right) \mathbf{1}\left\{b_{A}>p^{1}\right\} \mathbf{1}\left\{v_{B}^{2}>p^{2}\right\} \mid \beta\left(v_{B}^{1}\right)=b_{A}\right] \\
-\frac{\partial \beta^{-1}\left(b_{A}\right)}{\partial b_{A}} g_{v_{B}^{1}}\left(\beta^{-1}\left(b_{A}\right)\right) E\left[\max \left(v_{A}^{2}-v_{B}^{2}-\delta, 0\right) \mathbf{1}\left\{b_{A}>p^{1}\right\} \mathbf{1}\left\{v_{B}^{2}+\delta>p^{2}\right\} \mid \beta\left(v_{B}^{1}\right)=b_{A}\right] \\
+f_{p^{1}}\left(b_{A}\right) E\left[\max \left(v_{A}^{2}-v_{B}^{2}-\delta, 0\right) \mathbf{1}\left\{v_{B}^{2}+\delta>p^{2}\right\} \mathbf{1}\left\{\beta\left(v_{B}^{1}\right)>b_{A}\right\} \mid p^{1}=b_{A}\right] \\
\quad-f_{p^{1}}\left(b_{A}\right) E\left[\max \left(v_{A}^{2}-v_{B}^{2}, 0\right) \mathbf{1}\left\{v_{B}^{2}>p^{2}\right\} \mathbf{1}\left\{\beta\left(v_{B}^{1}\right)>b_{A}\right\} \mid p^{1}=b_{A}\right]
\end{gathered}
$$

where $f_{p^{1}}($.$) and g_{v_{B}^{1}}($.$) are the density functions of p^{1}$ and $v_{B}^{1}$. Replacing $b_{A}$ by the equilibrium bid $\beta\left(v_{A}^{1}\right)$, we find the following necessary condition for player $A$ to bid his willingness to pay in the first auction.

Proposition 1. In a sequential Vickrey auction with two objects and secret reservation prices, a necessary condition such that the optimal bidding strategy for player $A$ is $\beta\left(v_{A}^{1}\right)=v_{A}^{1}$ is:

$$
\begin{gathered}
g_{v_{B}^{1}}\left(v_{A}^{1}\right) E\left[\max \left(v_{A}^{2}+\delta-v_{B}^{2}, 0\right) \mathbf{1}\left\{v_{A}^{1}>p^{1}\right\} \mathbf{1}\left\{v_{B}^{2}>p^{2}\right\} \mid v_{B}^{1}=v_{A}^{1}\right] \\
-g_{v_{B}^{1}}\left(v_{A}^{1}\right) E\left[\max \left(v_{A}^{2}-v_{B}^{2}-\delta, 0\right) \mathbf{1}\left\{v_{A}^{1}>p^{1}\right\} \mathbf{1}\left\{v_{B}^{2}+\delta>p^{2}\right\} \mid v_{B}^{1}=v_{A}^{1}\right] \\
+f_{p^{1}}\left(v_{A}^{1}\right) E\left[\max \left(v_{A}^{2}-v_{B}^{2}-\delta, 0\right) \mathbf{1}\left\{v_{B}^{2}+\delta>p^{2}\right\} \mathbf{1}\left\{v_{B}^{1}>v_{A}^{1}\right\} \mid p^{1}=v_{A}^{1}\right] \\
-f_{p^{1}}\left(v_{A}^{1}\right) E\left[\max \left(v_{A}^{2}-v_{B}^{2}, 0\right) \mathbf{1}\left\{v_{B}^{2}>p^{2}\right\} \mathbf{1}\left\{v_{B}^{1}>v_{A}^{1}\right\} \mid p^{1}=v_{A}^{1}\right]=0 .
\end{gathered}
$$

Of course a similar condition holds for agent $B$ to play $\beta\left(v_{B}^{1}\right)=v_{B}^{1}$. If $\delta=0$ and if the second order conditions are verified, then it is clear that $\beta\left(v_{A}^{1}\right)=v_{A}^{1}$ and $\beta\left(v_{B}^{1}\right)=v_{B}^{1}$. That is, if the two objects are neither complements nor substitutes, the players' valuations (and hence bids) for the second object are not affected by the results of the first auction, and it is optimal for both players to bid their willlingness to pay in the first auction. Since the hypothesis $\delta=0$ may well be unrealistic in our experimental study, the question arises whether the necessary condition of Proposition 1 also holds in cases where $\delta \neq 0$. Since it appears impossible (even after choosing specific distributions functions for the random variables in our model) to derive an explicit solution for the optimal strategy $\beta($.$) , we answer this question via a Monte Carlo experiment.$ We simulated valuations by assuming that $v_{B}^{1}$ and $v_{B}^{2}$ are distributed as lognormal variates with means, standard errors and correlation coeficient equal to what is observed in our total sample (for wines 1 and 2). The valuations for wines 1 and 2 of player $A$ are equal to means of the bids (for wines 1 and 2 ). The reservation prices $p^{1}$ and $p^{2}$ are also simulated using the log-normal distribution: here the means are equal to the true reservation prices of wine 1 and 2 (see section 2), and the standard errors and correlation coefficient are the same as those chosen for the distribution of $\left(v_{B}^{1}, v_{B}^{2}\right)$. Two main results are to be drawn from this exercise. First, the condition of Proposition 1 is indeed verified for a very large range of values for $\delta$. Thus, at least for the valuations of $A$ that we have chosen in the simulations, there were many values for $\delta$ compatible with the first order condition of Proposition 1. Second, few bids were above the reservation prices fixed by us, i.e. few objects were actually sold 
in our Monte Carlo study. We shall return to this second finding in the next section.

Before turning to the empirical results, it should be mentioned that our simplifying assumption regarding the number of players can be weakened without altering the main conclusions of this section in a fundamental way. The hypothesis that $\delta$ is the same for all agents can also be dropped, the only consequence would be that the equilibrium strategies are no longer symmetric. Generalizing the model to the case of $k>2$ sequential auctions seems the most difficult extension. But even in this more complicated case it seems likely that there exist conditions (analogous to the conditions in Proposition 1) under which it is optimal for all bidders to bid their private values in all auctions.

\section{Results}

Some summary statistics for the socio-economic variables are given in Table $1 .{ }^{8}$ The indicator variables Nationality, Income, and Consumption were created by grouping the observed answers to questions 2, 5 and 7 into two classes. Question 6 is not exploited since all subjects responded they drank red wine.

[Table 1 about here]

In Table 2 we report summary statistics for the wine grades. From the last column it can be seen that in the sample as a whole the wine with the highest average score was wine 4 , while the wine with the lowest average score was wine 1. Looking at the results per room, we see that in room 1 wine 3 was the wine with the highest average grade, while in rooms 2 and 3 it was wine 4 ; the wine with the lowest average grade was wine 1 in room 1 , wine 3 in room 2 , and wine 2 in room 3. The lowest grade assigned by the subjects was 2 . This grade was one time assigned in room 1 (to wine 1), and three times in room 3 (once to wine 1 and twice to wine 2). The highest grade was 10 , the highest possible score. It was assigned two times in room 1 (once to wine 3 and once to wine 4), and two times in room 2 (to wine 4 ).

[Table 2 about here]

Table 3 reports summary statistics for the bids. From the last column it can be seen that on average the bids were highest for wine 4 , and lowest for wine 1. This also holds when we consider the results per room. Looking at the mean bids per wine, it appears that for all wines the bids were highest in room 2, and lowest in room 3. The highest submitted bid was FFr1207. This bid was submitted by a subject in room 2 for wine 4 . However, this subject did not win the wine, since the second highest bid was (just) below our reservation price. The lowest bid was FFr0, and was submitted by two subjects: one for wine 1

\footnotetext{
${ }^{8}$ The questionnaires were carefully and completely filled in by all subjects, so there are no missing observations for these variables, nor are there any missing values for the grades and the bids.
} 
in room 2, and one for wine 2 in room 3. Two subjects won a wine during the experiment. Both were in room 2. One subject won wine 1, and the other wine 3. Note that the relatively low number of successful auctions (the ones in which a wine was actually sold) is coherent with the findings of the Monte Carlo exercise reported in the previous section. These findings suggest that so few objects were sold because our reservation prices were too high. ${ }^{9}$

[Table 3 about here]

Table 4 contains summary statistics for the ranks of the wines. For each subject we assigned a rank to the wines on the basis of the subject's grades. For example, if a subject had graded the four wines with a 7, 8, 5 and 9 respectively, the rank we assigned to the wines was 3, 2, 4 and 1 respectively. If there were ties in the grades (for $44 \%$ of the subjects in the sample at least two grades were tied), we also tied the corresponding ranks. For instance, if the two best rated wines were tied, both wines were assigned a rank of 1.5. The conversion from grades to ranks is useful for at least two reasons. Whereas the wine grades assigned by an individual reflect her/his preferences, average grades such as those reported in Table 2 do not necessarily reflect group preferences. ${ }^{10}$ Group preferences can, however, be correctly inferred from the average ranks in Table 4. The issue is not that important in our data set though, since the ranking of wines according to average grades and the ranking according to average ranks lead to conflicting conclusions in room 2 only.

\section{[Table 4 about here]}

The second reason why the conversion is useful is that it allows us to apply several tests based on rank statistics from which more can be learned about the behavior of the subjects. Following Quandt (1998), we can test the hypothesis that the subjects in a room judged a wine neither good nor bad. This null hypothesis can be tested against the alternative hypothesis that the wine was good or against the hypothesis that it was bad. The test consists in comparing the sum (over all subjects in the room) of ranks of the wine with the critical value. If the rank sum is greater (smaller) than the upper (lower) critical value, it can be concluded that the wine was considered significantly good (bad). Similarly as in Quandt we computed the critical values using Monte Carlo simulations. We generated 5000 random rankings of four wines by $m$ subjects, ${ }^{11}$ calculated

\footnotetext{
${ }^{9}$ When the Monte Carlo study is performed by assuming that the reservation prices have means equal to the mean of the bids (for wine 1 and 2 ), the equilibrium bids are often above the reservation prices, i.e. much more objects are sold under this configuration.

${ }^{10}$ Average grades do not necessarily reflect group preferences when there are scaling effects. To see this, consider a simple example with two wines, evaluated by just two subjects. Suppose the first subject grades wine 1 with a 10 and wine 2 with a 1 , and that the second subject grades the wines with a 9 and a 10. The resulting average scores for wine 1 and wine 2 are 9.5 and 5.5 respectively. Although the subjects have opposite preferences -the first subject prefers wine 1 and the second subject wine 2 - the average grades wrongly suggest that there is a group preference for wine 1.

${ }^{11}$ Similarly as in Quandt the simulated ranks assigned by a subject were not allowed to be tied.
} 
for each of the 5000 replications the rank sums of the four wines, and chose the upper (lower) critical value at the $\alpha \%$ level such that for $\alpha \%$ of the replications at least one rank sum was greater (smaller) than the chosen critical value. This was done for $m=10,11$ and $\alpha=5,10$. The test results are given in Table 5 . In room 1 the subjects judged wine 1 significantly bad at the $5 \%$ level; in the other two rooms no wine was considered bad or good at that significance level. At the $10 \%$ level two additional rank sums are significant: wine 3 was considered good in room 1, and wine 4 was considered good in room 3.

\section{[Table 5 about here]}

We can also test the null hypothesis that the subjects in a room had ranked the wines in a random way, i.e. that the average ranks observed in a room was the result of pure random behavior. The alternative hypothesis is that the wines were ranked in a non-random way. Quandt (1998) suggested to construct a test on the basis of the statistic

$$
D=\sum_{j=1}^{n}\left(s_{j}-\frac{m(n+1)}{2}\right)^{2}
$$

where $n$ denotes the number of wines that were evaluated, $m$ the number of subjects, and $s_{j}$ the rank sum for wine $j$. It is not difficult to show that under the null hypothesis the expected value of $s_{j}$ is $m(n+1) / 2$ for each $j$. Hence the statistic $D$ tends to be smaller when the null hypothesis is true than when it is false, suggesting that a natural test is to reject the null hypothesis if $D$ is larger than some critical value. Again we resorted to Monte Carlo simulations to determine the critical value. Using the same simulated samples as above, we calculated $D$ for each replication, and the critical value at the $\alpha \%$ level was set equal to the $(1-\alpha \%)$-th quantile of the empirical distribution function of the $D$ 's. This was done for $m=10,11$ and $\alpha=5,10$. As Table 5 indicates, the only ranking that was significantly non-random at the $5 \%$ level was the one in room 1 . At the $10 \%$ level the rankings in rooms 1 and 3 were significantly non-random.

Table 6 reports the estimation results of the following bid-equation

$$
\begin{aligned}
\operatorname{Bid}_{i j}= & \beta_{1}+X_{i}^{\prime} \beta_{2}+\gamma_{j}+\text { Room }_{i} \theta_{1}+\text { Room }_{i} \theta_{2}+\text { Room }_{i} \theta_{3}+\varepsilon_{i j}, \\
& i=1, \ldots, 32, j=1, \ldots, 4,
\end{aligned}
$$

where $B i d_{i j}$ is the bid submitted by subject $i$ for wine $j ; \beta_{1}, \gamma_{j}, \theta_{1}, \theta_{2}$, and $\theta_{3}$ are scalar parameters, and $\beta_{2}$ is a vector of parameters; $X_{i}$ is a vector containing the socio-economic characteristics of subject $i$, and Room $1_{i}, R o o m 2_{i}$ and Room $3_{i}$ are dummy variables indicating the room to which subject $i$ was assigned; $\varepsilon_{i j}$ is an error term. Normalizing $\gamma_{1}=0$ and $\theta_{1}=0, \gamma_{2}, \gamma_{3}$ and $\gamma_{4}$ represent the effects of respectively wines 2,3 and 4 on the expected willingness to pay relatively to wine $1 ; \theta_{2}$ and $\theta_{3}$ represent the effects of respectively Room 2 and Room 3 on the expected willingness to pay relatively to Room 1 . Note that it is assumed that the two treatment effects do not depend on the type of wine. Since for each 
possible pair of rooms the difference between mean submitted bids was more or less the same for each wine (at least their signs were the same; see Table 3 ), this assumption seems reasonable. Note also that randomization ensures that the error term is independent from the room indicators. Assuming that the error term $\varepsilon_{i j}$ is i.i.d. over $i$ and $j$, independent from $X_{i}$, and with mean zero and variance $\sigma^{2}$, the parameters were estimated by OLS estimation. When other methods such as GLS random-effects estimation or ML random-effects estimation were used, i.e. methods that allow the error terms for a subject to be dependent random variables, the results were not fundamentally different. The results are analyzed under the assumption that all bids submitted by the subjects were equal to their willingness to pay for the wines, i.e. we assume that the necessary conditions of Proposition 1 are satisfied.

[Table 6 about here]

Let us first look at the estimation results for $\beta_{2}$, the parameters associated with the socio-economic variables. The estimates for Gender and Income are significantly negative and are of the same order of magnitude: the willingness to pay for wine is FFr115 less for women, and is FFr117 less for individuals belonging to a high income-household. Since all subjects in the sample had a job, i.e. all subjects disposed of a personal income, and since we control for household income and the size of the household, it is likely that the estimate for Gender reflects the pure intrinsic effect of being female on willingness to pay. The coefficient associated with Consumption is significantly positive: the willingness to pay is FFr132 more for individuals that regularly drink red wine than for individuals that only drink sporadically. The coefficient estimates of Age, Nationality, and Number of persons in household are not significant. The result for Nationality is quite surprising, since it suggests that French individuals value the Bordeaux wines and Burgundy wines similarly as individuals with a different nationality. The coefficients for the three wine indicators are all significant (although $\gamma_{2}$ only at the $10 \%$ level) and positive, implying that wine 1 is valued less than the other three wines. F-tests indicate that wines 2 and 3 are equally valued; wines 3 and 4 are also equally valued and wine 2 is valued less than wine 4 . Now consider the estimation results for the parameters of primary interest, i.e. the two treatment parameters. The coefficient for Room2 is positive but not statistically different from zero. This implies that once individuals have read the label characteristics and have consulted wine guides, the sensory characteristics of the wine do not have an additional impact on their willingness to pay. The coefficient for Room3 is significantly negative: if individuals who have only tasted the wines blindly are informed about the label characteristics and about the opinions of wine specialists, their willingness to pay increases on average by FFr109. ${ }^{12}$

\footnotetext{
${ }^{12}$ Admittedly, the estimation of the bid-equation reported here is based on a relatively low number of observations. To check whether any single observation had a disproportional effect on the estimates, we performed the eyeball test suggested in Davidson and MacKinnon (1993, pp. 32-33). The test does not suggest that there is an influential observation in our sample.
} 


\section{Conclusion}

This paper is based on an experimental auction during which four high-quality wines (two Bordeaux and two Burgundy wines) were sold in four separate sealed bid second-price auctions with secret reservation prices. This wine auction generated, for each individual, a set of socio-economic characteristics, four grades and four submitted bids for the wines. These data allow us to show that certain socio-economic variables such as gender, income and consumption habits, have a significant impact on the willingness to pay for wine, while others such as age and nationality do not. The data also allow us to establish how the willingness to pay differs with the degree of information that is available to the consumer. The sensory characteristics of the wine do not have a significant impact on the willingness to pay of individuals who have read the label of the bottle and the additional information. Conversely, the willingness to pay of individuals who have tasted the wines blindly increases significantly when they are informed about the label characteristics and the additional information.

The consumer's willingness to pay for wine is thus more closely related to the information reported on the label of the bottle and in wine guides than to the taste of the wine. More precisely, it seems that the description provided by the label and the experts outclasses the information that a typical consumer can gather through a simple blind-tasting. A possible explanation for this result could be the following. Basically, wine can be considered as a bundle of characteristics or attributes. Some of these characteristics are search attributes and some others are experience attributes. ${ }^{13}$ The former, the label characteristics, can be evaluated by the consumers before they buy the wine, by examining and researching the product. The latter, the sensory characteristics, are attributes that consumers cannot assess until they buy and taste the wine. However, it is difficult for non experts to perceive the sensory characteristics and more generally to determine accurately the quality of a wine. This is especially true for young wines, as those used in our experiment, the quality of which can be expected to be underestimated. A simple way for consumers to be informed about the quality of a wine is then to consider the label characteristics as quality indicators or to read the opinions of wine specialists. Actually, wine guides and labels provide the consumers an information about quality that is respectively better and easier to identify than the one they can obtain through their own tasting of the product. Therefore, tasting a wine after reading the label of the bottle and the experts' opinions does not bring any additional information on the product and thus does not alter the willingness of consumers to pay. But reading these opinions and the label after the tasting of the wine gives the consumers an information that they are not able to get through their own evaluation, explaining then the revision (the increase in the case of young wines) of their willingness to pay.

It would be interesting to see if the conclusions of this study are confirmed using a larger population and other types of wines (more mature wines, less

\footnotetext{
${ }^{13}$ See Nelson $(1970,1974)$ for the distinction between search and experience goods, and Caswell and Mojduszka (1996) for its application to product characteristics.
} 
expensive wines, other wine regions, etc.). Another topic for further research is to announce information on prices such as the retail price in the experiment. 


\section{References}

[1] Ashenfelter, Orley. "How Auctions Work for Wine and Art." Journal of Economic Perspectives, Summer 1989, 3 (3), pp. 23-36.

[2] Bernhardt, Dan and Scoones, David. "A Note on Sequential Auctions." American Economic Review, June 1994, 84 (3), pp. 653-657.

[3] Black, Jane and de Meza, David. "Systematic Price Differences Between Successive Auctions are no Anomaly." Journal of Economics and Management Strategy, December 1992, 1 (4), pp. 607-628.

[4] Caswell, Julie A. and Mojduszka, Eliza M. "Using Informational Labeling to Influence the Market for Quality in Food Products." American Journal of Agricultural Economics, December 1996, 78 (5), pp. 1248-1253.

[5] Combris, Pierre, Lecocq, Sébastien and Visser, Michael. "Estimation of a Hedonic Price Equation for Bordeaux Wine: Does Quality Matter?" Economic Journal, March 1997, 107 (1), pp. 390-402.

[6] Davidson, Russell and MacKinnon, James G. Estimation and inference in econometrics. Oxford: Oxford University Press, 1993.

[7] Engelbrecht-Wiggans, Richard. "Sequential Auctions of Stochastically Equivalent Objects." Economics Letters, February 1994, 44 (1-2), pp. 8790 .

[8] von der Fehr, Nils-Henrik M. and Riis, Christian. "Option Values in Sequential Markets." Mimeo, University of Oslo, 1999.

[9] Gale, Ian L. and Hausch, Donald B. "Bottom-Fishing and Declining Prices in Sequential Auctions." Games and Economic Behavior, November 1994, 7 (3), pp. 318-331.

[10] Ginsburgh, Victor. "Absentee Bidders and the Declining Price Anomaly in Wine Auctions." Journal of Political Economy, December 1998, 106 (6), pp. 1302-1319.

[11] Kagel, John H. "Auctions: a Survey of Experimental Research," in John H. Kagel and Alvin E. Roth, eds., The handbook of experimental economics. Princeton: Princeton University Press, 1995, pp. 501-585.

[12] Lucking-Reiley, David. "Using Field Experiments to Test Equivalence Between Auction Formats: Magic on the Internet." American Economic Review, December 1999, 89 (5), pp.1063-1080.

[13] McAfee, R. Preston and Vincent, Daniel. "The Declining Price Anomaly." Journal of Economic Theory, June 1993, 60 (1), pp. 191-212. 
[14] Nelson, Phillip. "Information and Consumer Behavior." Journal of Political Economy, March/April 1970, 78 (2), pp. 311-329.

[15] Nelson, Phillip. "Advertising as Information." Journal of Political Economy, July/August 1974, 82 (4), pp. 729-754.

[16] Quandt, Richard E. "Measurement and Inference in Wine Tasting." Mimeo, Princeton University, 1998.

[17] Vickrey, William. "Counterspeculation, Auctions, and Competitive Sealed Tenders." Journal of Finance, March 1961, 16 (1), pp. 8-37.

[18] Weber, Robert J. "Multiple-Object Auctions," in R. Engelbrecht-Wiggans, M. Shubik, and R.M. Stark, eds., Auctions, bidding, and contracting: uses and theory. New York: New York University Press, 1983, pp. 165-191. 


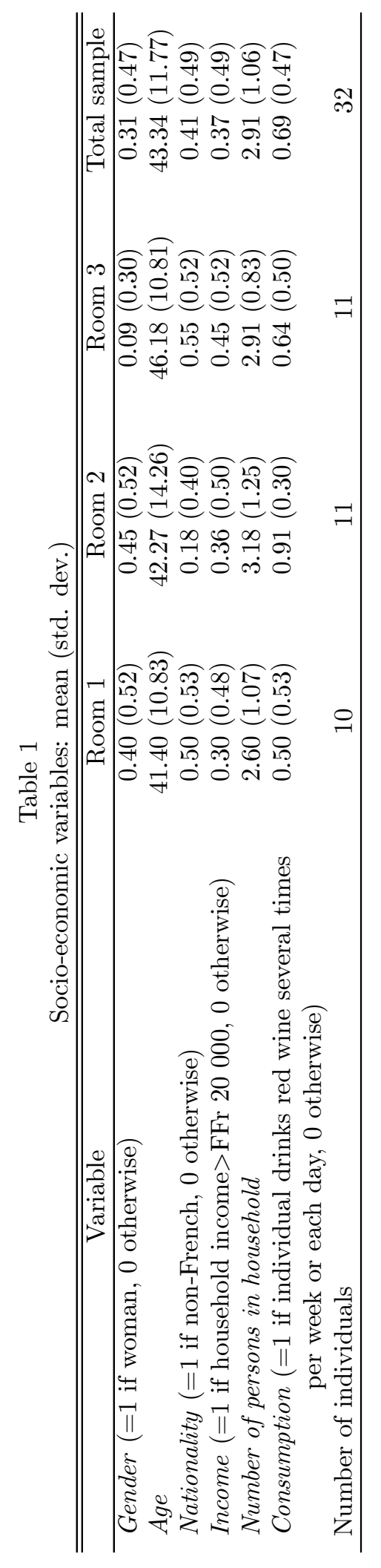


Table 2

Grades on a 0-10 scale: mean (std. dev.)

\begin{tabular}{ccccc}
\hline \hline Wine & Room 1 & Room 2 & Room 3 & Total sample \\
\hline 1 & $4.30(1.64)$ & $6.82(1.25)$ & $5.18(1.72)$ & $5.47(1.83)$ \\
2 & $6.50(1.43)$ & $7.00(1.48)$ & $5.00(2.19)$ & $6.16(1.90)$ \\
3 & $7.70(1.06)$ & $6.55(1.29)$ & $6.09(1.38)$ & $6.75(1.39)$ \\
4 & $7.10(1.73)$ & $7.18(1.99)$ & $6.91(1.22)$ & $7.06(1.63)$ \\
\hline
\end{tabular}

Table 3

Bids for a lot of 6 bottles in FFr: mean (std. dev.)

\begin{tabular}{ccccc}
\hline \hline Wine & Room 1 & Room 2 & Room 3 & Total sample \\
\hline 1 & $152(109)$ & $266(301)$ & $145(101)$ & $189(198)$ \\
2 & $292(198)$ & $310(126)$ & $199(203)$ & $266(180)$ \\
3 & $308(116)$ & $404(188)$ & $216(88)$ & $310(156)$ \\
4 & $356(258)$ & $467(319)$ & $243(93)$ & $356(253)$ \\
\hline
\end{tabular}

Table 4

Ranks of wines: mean (std. dev.)

\begin{tabular}{ccccc}
\hline \hline Wine & Room 1 & Room 2 & Room 3 & Total sample \\
\hline 1 & $3.95(0.16)$ & $2.45(1.08)$ & $2.86(1.03)$ & $3.06(1.06)$ \\
2 & $2.55(0.64)$ & $2.23(1.01)$ & $3.00(1.18)$ & $2.59(1.00)$ \\
3 & $1.70(0.79)$ & $2.95(0.91)$ & $2.41(0.97)$ & $2.38(1.01)$ \\
4 & $1.80(0.82)$ & $2.36(1.32)$ & $1.72(0.88)$ & $1.97(1.05)$ \\
\hline
\end{tabular}


Table 5

Rank sums and the $D$-statistic

\begin{tabular}{clll}
\hline \hline Wine & Room 1 & Room 2 & Room 3 \\
\hline 1 & $39.5^{--}$ & 27 & 31.5 \\
2 & 25.5 & 24.5 & 33 \\
3 & $17^{+}$ & 32.5 & 26.5 \\
4 & 18 & 26 & $19^{+}$ \\
\hline$D$ & $323.5^{* *}(122 ; 100)$ & $36.5(140 ; 115)$ & $119.5^{*}(140 ; 115)$ \\
\hline
\end{tabular}

Notes: Significance levels for the rank sums were computed using Monte Carlo simulations. In room 1 (10 subjects and 4 wines), the critical lower (upper) value at the $5 \%$ level is equal to 17 (33); at the $10 \%$ level the lower (upper) value equals 18 (32). In rooms 2 and 3 (11 subjects and 4 wines), the lower (upper) value at the $5 \%$ level is 19 (36), and at the $10 \%$ level $20(35)$. ++ (--) indicates a significantly good (bad) wine at the $5 \%$ level; $+(-)$ indicates a significantly good (bad) wine at the $10 \%$ level. Critical levels for $D$ were also computed using Monte Carlo simulations and are given in parentheses $(5 \% ; 10 \%) . * *(*)$ indicates a significant value for $D$ at the $5 \%(10 \%)$ level.

Table 6

OLS results for the bid equation

\begin{tabular}{|c|c|c|}
\hline Variable & Estimate & T-statistic \\
\hline Constant $\left(\beta_{1}\right)$ & 219.95 & 2.34 \\
\hline Gender & -115.37 & -2.93 \\
\hline Age & -1.12 & -0.69 \\
\hline Nationality & 16.62 & 0.45 \\
\hline Income & -117.10 & -3.25 \\
\hline Number of persons in household & 7.52 & 0.48 \\
\hline Consumption & 131.85 & 3.53 \\
\hline Wine2 $\left(\gamma_{2}\right)$ & 77.19 & 1.77 \\
\hline Wine3 $\left(\gamma_{3}\right)$ & 120.25 & 2.76 \\
\hline Wine $4\left(\gamma_{4}\right)$ & 166.41 & 3.82 \\
\hline $\operatorname{Room2}\left(\theta_{2}\right)$ & 46.77 & 1.06 \\
\hline Room3 $\left(\theta_{3}\right)$ & -109.36 & -2.70 \\
\hline Number of observations & \multicolumn{2}{|c|}{128} \\
\hline$\sigma$ & \multicolumn{2}{|c|}{174.26} \\
\hline Adjusted $R^{2}$ & \multicolumn{2}{|c|}{0.29} \\
\hline
\end{tabular}




\title{
Appendix 1: Letter to participants
}

(the letter was the same in the three rooms except where indicated)

\author{
E NOMETRICS $-6^{\text {th }}$ Conference
}

An Experimental Wine Auction

Ajaccio, 2 October 1998

Dear colleague,

In a short while an experimental wine auction will take place in this conference room. The aim of this experiment is to analyze the impact of information on the formation of auction prices. The purpose of this letter is to inform you about the conditions under which the experiment will be held.

There are several conference rooms, and each person attending this conference has been randomly assigned to one of them. In each room the experimental conditions will be slightly different.

\section{Room 1.}

You have been assigned to room 1. In room 1 the experiment will start with an evaluation of four different wines. You will get the opportunity to taste the four wines, and read the label of the bottles as well as some additional information concerning the products.

\section{Room 2.}

You have been assigned to room 2. In room 2 the experiment will start with an evaluation of four different wines. You will only get the opportunity to read the label of the bottles as well as some additional information concerning the products.

\section{Room 3.}

You have been assigned to room 3. In room 3 the experiment will start with an evaluation of four different wines. You will only get the opportunity to taste blindly the four wines.

You will be asked to grade each wine on a scale from 0 to 10, and report the grade on a form. On this form you will also be asked to answer a number of questions about your wine consumption habits, and some questions about your socio-economic characteristics (more precisely, we will ask you your age, your gender, your nationality, the size of your household, and your household income).

The four wines will then be sold (per lot of six bottles) at a so-called second-price sealed bid auction (also known as a Vickrey auction).

\section{Room 1.}

The wines will be auctioned successively, and you will only compete with participants in room 1.

\section{Room 2.}

The wines will be auctioned successively, and you will only compete with participants in room 2 .

\section{Room 3.}

The wines will be auctioned successively, and you will only compete with participants in room 3 .

For each wine, you will be requested to submit a bid in an envelope. The wine will only be sold if the second highest bid exceeds or equals a secret reservation price fixed by us. If that is the case, the participant with the highest bid will win the wine and will pay a price equal to the second highest bid.

We guarantee that all information obtained in this experiment will remain strictly confidential at all times. That is, if you decide to participate in the experiment, your bids and the information concerning your wine consumption habits and socio- 
economic characteristics will not be revealed to the other participants of the conference, nor will it be possible to identify you in whatever way from future publications based on the experimental data set.

If you accept the above conditions and if you are willing to participate in the experiment, we ask you to sign this letter.

(first name and surname)

(signature) 


\section{Appendix 2: Instructions for participants (instructions were the same in the three rooms except where indicated)}

First we will ask you a number of questions concerning your socio-economic characteristics and your wine consumption habits. Please find (among the material that was included in the big envelope) the questionnaire form, and answer the questions in parts $\mathrm{A}$ and $\mathrm{B}$ (do not answer the questions in part $\mathrm{C}$ yet).

Now that you have answered the questions in parts A and B, we will turn to the evaluation of the four wines.

\section{Room 1.}

Please find the four wine description forms. Each form is numbered 1, 2, 3, or 4, and contains a photo of the label of the wine bottle as well as some additional information concerning the product. Please look at each form carefully. After you have read the wine descriptions, you will be served four cups of wine. Each cup is numbered, again between 1 and 4 . There is a one-to-one correspondence between cups and wine descriptions, i.e. the wine in say cup $\mathrm{j}$ corresponds to the wine described in form $\mathrm{j}$. Please taste each wine... You will now be required to grade each wine in view of its description form and its taste.

\section{Room 2.}

You will get the opportunity to read the label of the wine bottles as well as some additional information concerning the products, but you will not be able to actually taste the wines. Please find the four wine description forms. Each form is numbered 1, 2,3, or 4, and contains a photo of the label of the wine bottle plus the additional information. Please look at each form carefully... You will now be required to grade each wine in view of its description form.

\section{Room 3.}

You will be able to taste the wines, but you will not get the opportunity to read the label of the wine bottles nor any other information concerning the products. You will be served four cups of wine. Each cup is numbered 1, 2, 3, or 4. Please taste each wine... You will now be required to grade each wine in view of its taste.

Please grade each wine on a scale from 0 (very bad) to 10 (very good), and report all grades in part $\mathrm{C}$ of the questionnaire form. Since the questionaire forms will now be collected, we advise you to copy your grades on a separate piece of paper, as they might be useful in determining your bids for the wines later on.

The wines you have just evaluated will be auctioned separately, first we will auction wine 1, then wine 2, etc... Each wine will be sold, per lot of six bottles, at a Vickrey auction with a secret reservation price fixed by us. According to this auction mechanism, a wine will only be sold if the second highest bid is equal to or larger than the secret reservation price. If that is the case, the participant with the highest submitted bid will win the wine, and will pay a price equal to the second highest bid. (Example 1: suppose there are four participants with bids equal to 50, 30,70 and 60 respectively, and suppose the reservation price is 40 , then participant three wins and pays a price equal to 60 . Example 2: suppose there are four participants with bids equal to 70,80, 20 and 110 respectively, and suppose the reservation price is 90 , then nobody wins the auction since the reservation price exceeds the second highest bid.)

The winner of an auction will pay the winning price to us. The bottles of wine will be sent to her/his home address without any additional charges.

The reservation prices are equal to the wholesale prices of the wines. The reservation prices are included in the four envelopes I show you now, but they will be kept secret during the experiment. At the end of the session you can, if you wish, consult the envelopes and read our reservation prices.

You will be able to submit your bid for a particular wine by picking the appropriate small envelope (there are four of them, each one numbered between 1 and 4), by indicating on the included piece of paper your bid, and by reinserting the piece of paper in the small envelope (please do not close it). Remember that your bid will be for a lot of 6 bottles, and should be in French francs. Remember also that you will only compete with the participants in this room.

As mentioned already, the wines will be auctioned successively, one after the other. Once all bids for a particular wine are submitted, we will collect the envelopes and compare the bids. If there is no winner, we will directly move on to the next auction round. If there is one, I will announce the winner's identification number, ask the winner to come to me and reveal her/his name, and then we will continue with the next round. In case the highest bid is submitted by two or more participants simultaneously (and if at the same time the second highest bid is equal to or larger than the reservation price), we will select the winner at random among these participants.

You will now have the opportunity to read the instructions on your own and ask questions. Once there are no more questions, we will proceed with the sale by auction of wine 1 .

Please submit your bid for wine 1 . 


\section{Appendix 3: Questionnaire}

\section{A. $\underline{\text { Socio-economic questions }}$}

1. What is your gender?

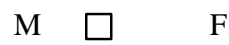

2. What is your nationality?

3. What is your age?

4. How many people live in your household?

5. What is your monthly net (after taxes) household income in French francs?

$\begin{array}{llllll}0-5000 & \square & 5000-10000 & \square & 10000-15000 & \square \\ 15000-20000 & \square & 20000-25000 & \square & 25000-30000 & \square \\ 30000-40000 & \square & 40000-50000 & \square & 50000-75000 & \square \\ 75000-100000 & \square & >100000 & \square & & \end{array}$

B. Consumption habits

6. Do you drink red wine?

Yes $\square \quad$ No

7. If yes, with which frequency?

Once per month

Once per week

Several times per week

Each day

C. Wine evaluation

8. How do you grade each wine on a $0-10$ scale?

Wine 1

Wine 2

Wine 3

Wine 4 


\section{Appendix 4: Wine description forms}

\section{Description wine 1}
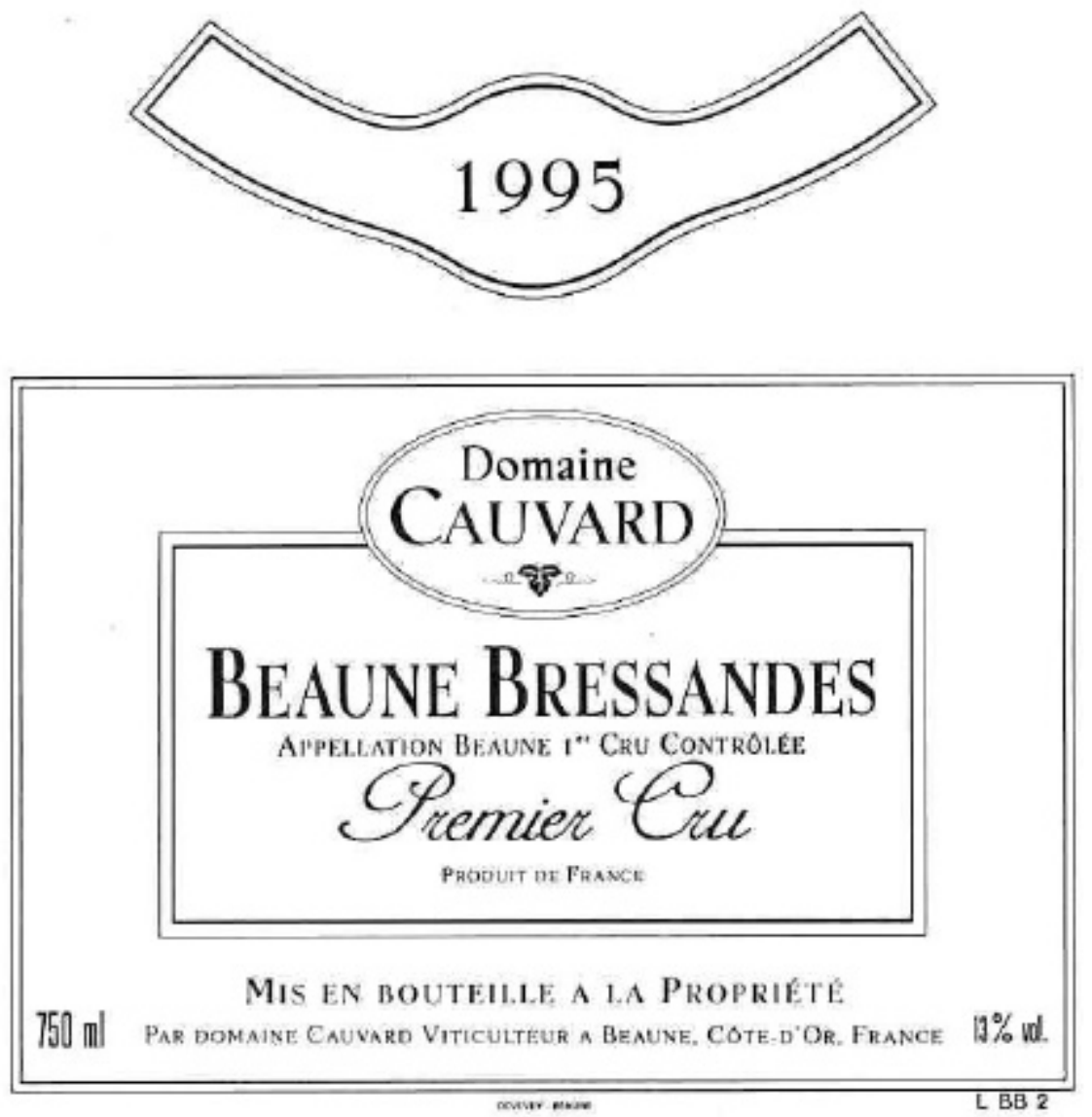

Beaune, a small village of 23000 inhabitants, is the wine capital of Burgundy and is well known for its cellars and "Hôtel Dieu'. The vineyard of Beaune stretches over a large band (of 1000 to 2000 metres) on gentle slopes (230 to 300 meters high). Added to its location, its latitude makes it one of the most early-ripening vineyards of the Côte d'Or. The soils, which are composed of brown limestone irregularly mixed with clay and sand, have an influence on the variety of the terroirs. One finds a range of wines going from supple and fine wines to firm and structured wines with a good ageing potential (Les $1^{\text {er }}$ Crus du vignoble de Beaune, 1998).

"L'appellation" Beaune counts 28 "Premiers crus" and 8 others that are only partially on its territory (total surface of Beaune region is 322 acres). Some of them - Les Epenottes, Le Clos des Mouches, Les Cent Vignes or Les Bressandes actually deserve a revalorization of their ranking (Bradfer, de Clouet, and Maratier, 1992). [Remark: “Appellations Premier cru" and "Grand cru" implies not only that the wines are of quality, but also that they are produced on a well demarcated parcel ("un climat"). Often the parcels are exploited by several wine producers with similar production methods.]

Domain Cauvard is a family property (3rd generation) that exploits 16.5 acres in Côtes de Beaune. Traditional methods are used together with new oenology-techniques ensuring a constant level of production and quality. Cauvard is one of the 10 principal owners of Bressandes, and exploits other "appellations Premier cru": Beaune Cent Vignes and Beaune Teurons, and an "appellation Grand cru" (a white wine): Corton Charlemagne (publicity of the owner).

Grape variety: Pinot noir. Time spent in cask: 12 months. Average age of vine: 50 years. Maturation period: 5 to 10 years, depending on the vintage.

The structure of the exploitations in the Côtes de Beaune is characterized by a multiplicity of small parcels, and by the fact that wine owners produce small quantities of wine. The procedures associated with referring in guides are then cumbersome and expensive, implying that for many producers there is no strong incentive to appear in them. It is the case for wine 1 , for which no guide appreciations exist. 


\section{Description wine 2}

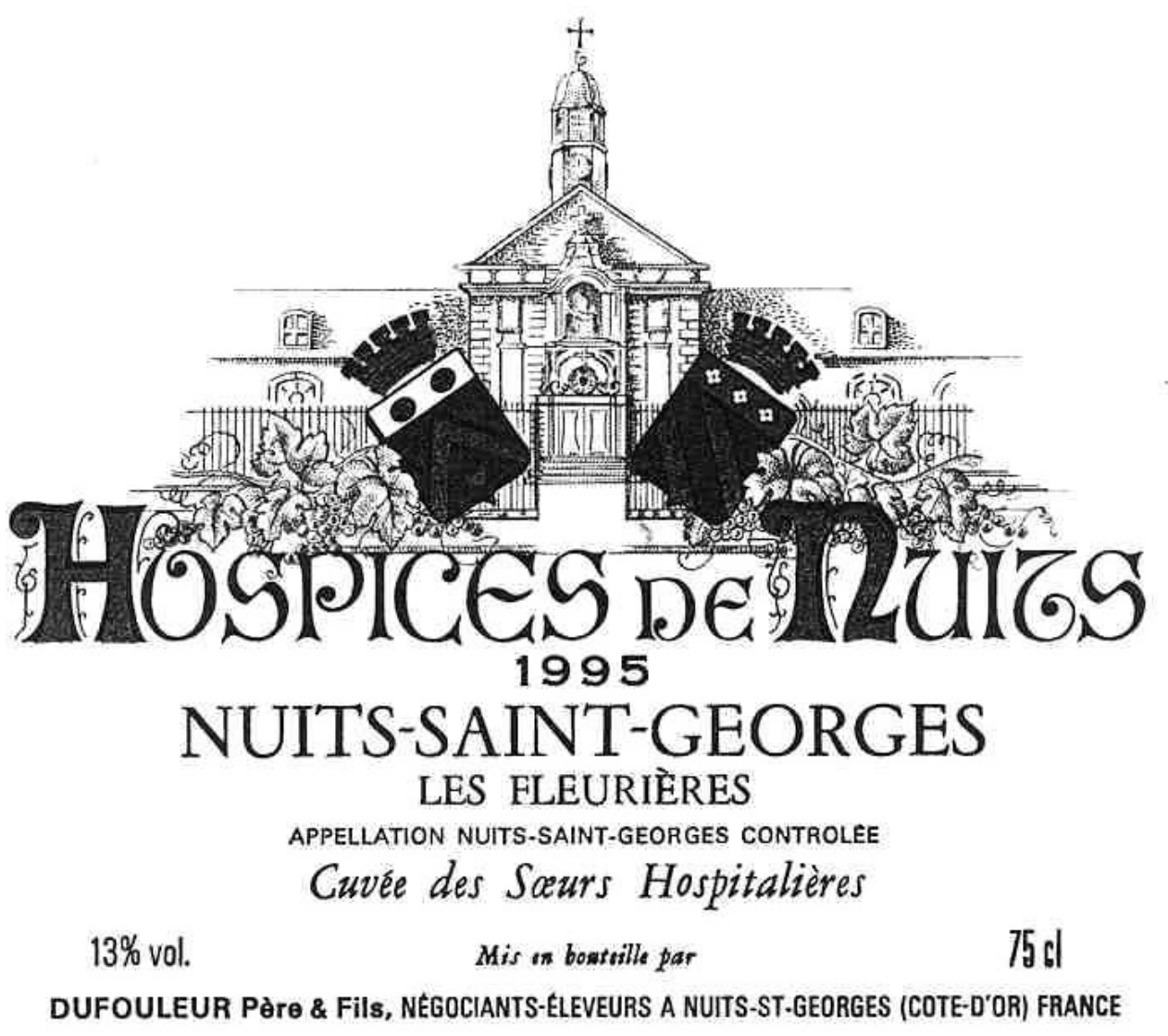

The vineyards of Nuits-Saint-Georges are located on the hill and the Piedmont. The total surface is 315 acres, of which 125 are Hautes Côtes de Nuits. The domain Hospices de Nuits-Saint-Georges was assembled over the years through bequests given by families living in the region. Nowadays, it stretches out over an area of 11.3 acres in the municipalities of Nuits-StGeorges, Prémaux-prissey and Vosne-Romanée. The wines are kept at the Hospices in new casks to guarantee quality; the whole wine production is bottled in the region (booklet Hospices de Nuits-St-Georges).

Les Fleurières is situated south of Nuits-Saint Georges, at the foot of the hill. The 1995 vintage of Les Fleurières has been sold at auction (charity sale) in March 1996. The buyers were Maison Liger-Belair, Maisons Jean-Luc Aergerter (Nuit-SaintGeorges) Bouchard Aîné France (Nuits-Saint-Georges), Gall (The Netherlands), Maison Charles Viennot (Nuit-SaintGeorges) in company with Maison Orange et Co (Jersey, Guernesey) and Jean-Claude Boisset Vins (Bienne, Suisse), and Weinkellerei Karl Weber (Cologne, Allemagne) (local journal , March 1996).

Production of Fleurières des Hospices: 8 to 11 "pièces" (of 228 liters each, or 300 bottles) depending on the vintage. Grape variety: Pinot noir. Vineyard: 9.5 acres. Time spent in cask: 18 to 20 months. Average age of vine: 40 years. Maturation period: 8 to 15 years for the 1995 vintage. Ranking: "Appellation Nuits-Saint-Georges Village".

The structure of the exploitations in the Côtes de Nuits is characterized by a multiplicity of small parcels, and by the fact that wine owners produce small quantities of wine. The procedures associated with referring in guides are then cumbersome and expensive, implying that for many producers there is no strong incentive to appear in them. It is the case for wine 2 , for which no guide appreciations exist. 


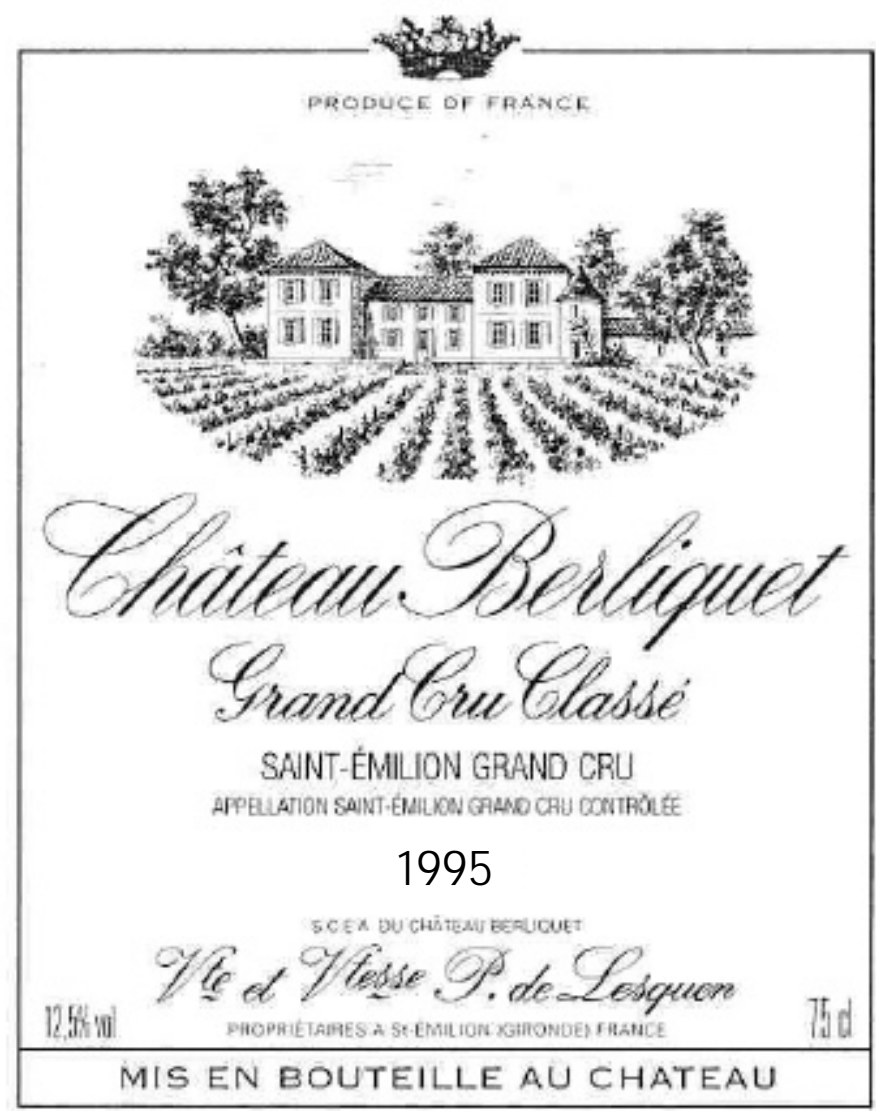

Production: 48000 bottles. Grape variety: Merlot (75\%); Cabernet sauvignon (15\%); Cabernet franc (10\%). Vineyard: 8.5 acres. Time spent in cask: 20 months. Average age of vine: 30 ans. Maturation period: 4 to 12 years, depending on the vintage. Ranking: "Grand cru classé”.

If there is one name which is known since centuries in Saint-Emilion, then it is definitely Berliquet. It was mentioned on very old geographical maps, and since 1767 Berliquet is considered as one of the most highly esteemed Saint-Emilion wines. The wine broker Paguierre, in his "Classification et Description des Vins de Bordeaux" published in 1829, indicated that the top Saint-Emilion wines were Canole, Berliquet, l'abbé Desèze, Laborie and Fontemoing. [...] This château has always put much effort in the improvement and renewing of its vineyard. Very recently the owners have installed a modern vat, allowing the alliance of the most recent production techniques and traditional vinification methods. The grapes harvest, on average forty barrels, matures in old casks, which are located under the château. Visiting these installations is not only majestically beautiful, but also allows one to realize how carefully the owners and those who actually produce the wines look after the place: their common and only concern is to please their highly demanding French and foreign customers. Château Berliquet is a member of "les vins de Bordeaux" (publicity of the owner).

This property has superb cellars, is remarkably situated and is very well exposed at the outskirts of Saint-Emilion. In 1985, Berliquet was the only chateau to be promoted "grand cru classé". Its reputation, however, seems to have been even greater in the XVIII-th century; in a manuscript dating from 1794, a courier from Libourne praised the excellent quality of this SaintEmilion wine. However, the domain has remained somewhat in the dark until 1978: the wines were then produced and distributed by the enormous cooperative of the city. Since then, the wine production and bottling take place at the château. [...] Estimation of its current rank: equivalent to a "cru bourgeois de Médoc" (Robert Parker, 1993).

The vineyard of château Berliquet stretches out over the famous Madelaine plateau. It neighbours those of châteaux Canon and Magdelaine. This privileged location and magnificent exposition give the wines a bouquet and a finesse, thanks to which château Berliquet has won the highest awards in the previous century (Claude Ferret, 1974). 


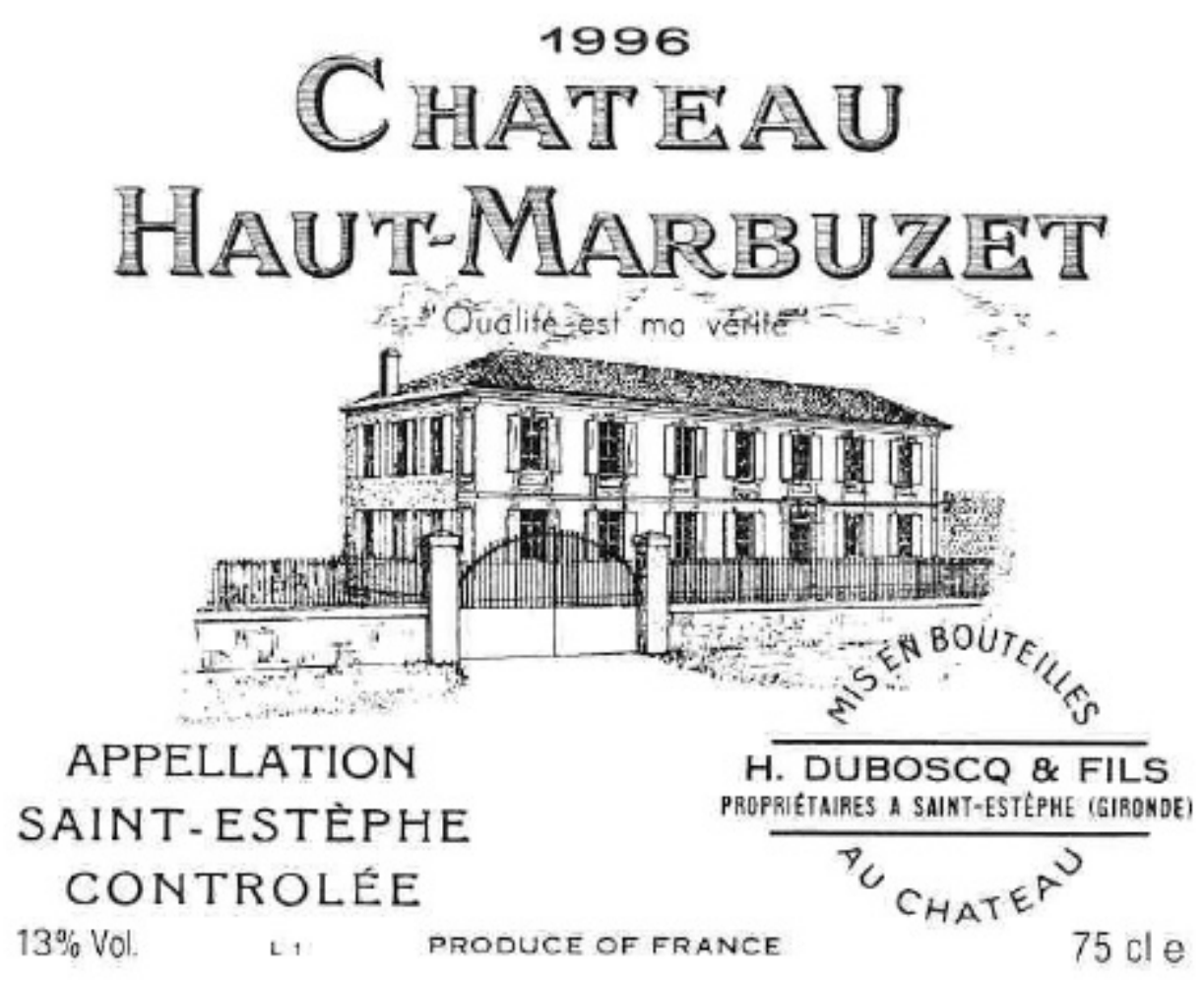

Production: 240000 bottles. Grape variety: Merlot (50\%); Cabernet sauvignon (40\%); Cabernet franc (10\%). Vineyard: 40 acres. Time spent in cask: 18 months. Average age of vine: 30 years. Maturation period: 3 to 15 years, depending on the vintage. Ranking: "Cru bourgeois"'.

Château Haut-Marbuzet figures on the menus of the best restaurants in Europe; it has more than 20000 regular clients, among who the presidency of the French republic, the Prime Minister's office ("l'hôtel Matignon"), the European parliament, the national assembly, the senate, several ministries, and many well known national and international personalities (publicity of the owner).

Haut-Marbuzet is one of the oldest properties in Saint-Estèphe, but it remained relatively unknown until 1952, when it was bought by the father of the actual owner, Henri Dubosq. [...] The vineyard is excellently situated, facing the valley of the Gironde on a gentle slope. Dubosq produces a bordeaux which is among the most sought after, particularly in France, in Belgium, in The Netherlands and in the UK (these four countries absorb the largest part of the production). He is a supporter of harvesting relatively late, so that the grapes are very ripe when gathered. He lets the grapes macerate for at least 3 weeks, and all his wines mature in casks made of new oak for a period of 18 months; these methods give rise to a wine that is very fruity, opulent and full, with a rich, exotic and spicy bouquet. For wine lovers, Haut-Marbuzet is not only one of the "easiest", but also one of the most sensual wines of the Bordeaux region. This bordeaux has a character a bit similar to a burgundy wine or a voluptuous côtes-du-rhône. [...] Estimation of its current rank : should be promoted "troisième grand cru classé"' (Robert Parker, 1993).

The best of many good St-Estèphe crus bourgeois. New oak gives Haut-Marbuzet a classic style (Hugh Johnson, 1995). Henri Dubosq, magician of wine, has always set the pace in the Médoc. One of the first bourgeois to use casks made of new oak for the entire wine production, he has succeeded in producing a very fashionable wine. [...]. In 1985 this wine has won the "Coupe des crus bourgeois" (Bradfer, de Clouet, and Maratier, 1992). 